WellBeing International

WBI Studies Repository

$8-2013$

\title{
Examining the Link Between Personality and Laterality in a Feral Guppy Poecilia reticulata Population
}

\author{
Eleanor Irving \\ Macquarie University \\ Culum Brown \\ Macquarie University
}

Follow this and additional works at: https://www.wellbeingintlstudiesrepository.org/acwp_asie

Part of the Animal Studies Commons, Comparative Psychology Commons, and the Other Animal Sciences Commons

\section{Recommended Citation}

Irving, E., \& Brown, C. (2013). Examining the link between personality and laterality in a feral guppy Poecilia reticulata population. Journal of fish biology, 83(2), 311-325.

This material is brought to you for free and open access by WellBeing International. It has been accepted for inclusion by an authorized administrator of the WBI Studies Repository. For more information, please contact wbisr-info@wellbeingintl.org.

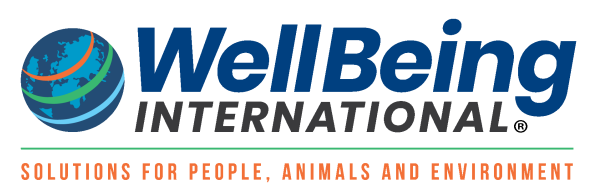




\title{
Examining the link between personality and laterality in a feral guppy Poecilia reticulata population
}

\author{
E. Irving and C. Brown \\ Macquarie University
}

\section{KEYWORDS}

activity, behavioural syndrome, life-history strategy, shy-bold continuum, sociability

\begin{abstract}
This study examined whether variation in the strength and direction of lateralization in a detour task was linked with variation in three common personality measurements: boldness, activity and sociability, in a population of wild guppies Poecilia reticulata. Additionally, the aim was to determine whether any consistent correlations between these behavioural traits, known as behavioural syndromes, were present in the study population. The results revealed that all three personality traits were highly repeatable over time in both sexes. Evidence of a complex syndrome in the form of a correlation between boldness, sociability and activity was found; however, this relationship was only present in males. Males that were more active in a familiar environment emerged more quickly from shelter into a novel environment and were more social. In general, male $P$. reticulate were bold, active and antisocial compared to females, with these differences probably a reflection of opposing life-history strategies. Only a weak link between the strength of cerebral lateralization and personality was discovered and this was mediated by sex.
\end{abstract}

\section{INTRODUCTION}

Cerebral lateralization was long thought to be unique to humans, heralded as the explanation for a whole host of phenomena including handedness, tool use and language (Rogers, 2002). Over the past few decades, however, a vast body of evidence has emerged for cerebral lateralization in other organisms, including mammals and birds (Casperd \& Dunbar, 1996; Rogers, 1996; Diekamp et al ., 2005), reptiles and amphibians (Bisazza et al ., 1998a, 2002; Robins et al ., 2005) and even some invertebrates (Byrne et al ., 2002; Heuts \& Brunt, 2005; Letzkus et al ., 2006). This supports a hypothesis of an ancient origin for cerebral lateralization, making fishes particularly interesting study organisms from an evolutionary perspective (Bisazza \& Brown, 2011). As many fishes do not possess overlapping optic fields, the direction and strength of lateralization can be easily assessed by observing asymmetries in eye preferences (Bisazza et al ., 1998b). A number of studies have exploited this, examining lateralization both within and across species with respect to social behavior (Bisazza et al ., 2000a; Bisazza \& Dadda, 2005; Reddon \& Balshine, 2010), sex (Bisazza et al ., 1998b; Reddon \& Hurd, 2009a), heritability 
(Bisazza et al ., 2000b, 2005; Brown et al ., 2007a) and experience (De Santi et al ., 2000; Brown et al ., 2004; Sovrano, 2004).

Much focus has been directed towards understanding the costs and benefits of cerebral lateralization, with field and laboratory studies demonstrating enhanced cognitive abilities in lateralized individuals (Rogers, 2000; Dadda et al ., 2009; Magat \& Brown, 2009). In particular, cerebral lateralization is thought to have been selected for the advantage it confers in situations where multiple stimuli must be processed simultaneously (Vallortigara \& Rogers, 2005). For instance, Dadda \& Bisazza (2006) showed that lateralized individuals of Giardinus falcatus (Eigenmann 1903) have a higher rate of prey capture than non-lateralized individuals in the presence of a predator, with this difference disappearing when the predator is no longer visible. At the population level, lateralization is believed to have developed in response to the selective pressures associated with a social lifestyle (Brown, 2005). In a study examining 16 species of fishes, population-level lateralization was observed in $100 \%$ of the gregarious species, compared to just $40 \%$ of the non-gregarious ones (Bisazza et al ., 2000a).

Despite the known advantages of cerebral lateralization, most species exhibit significant individual variation in both the strength and direction of lateralization (Bisazza \& Brown, 2011). The direction of lateralization has received the bulk of attention in the literature, with frequency-dependent selection put forth as an explanation for the maintenance of variation (Hori, 1993; Ghirlanda \& Vallortigara, 2004; Brown, 2005). From a genetic and evolutionary perspective, however, the strength of lateralization is likely to be more illuminative, with non-lateralized individuals surprisingly common in many species (Dinsdale et al ., 2011). In spite of this, variation in the strength of lateralization remains largely unexplored (Reddon \& Hurd, 2009b).

A recent hypothesis for how variability in the strength of lateralization may be maintained, proposes a link between laterality and consistent inter-individual differences in behaviour (Reddon \& Hurd, 2009b). In humans, males displaying a strong level of handedness have been shown to be more aggressive than males who are ambidextrous (Dinsdale et al ., 2011). Aggressiveness seems to be highly lateralized in a wide range of vertebrates ranging from primates to fishes (Rogers \& Andrew, 2002). Reddon \& Hurd (2008) demonstrated a sex-dependent relationship between lateralization and aggressiveness in the convict cichlid Amatitlania nigrofasciata (Gunther 1867). Populations of the poeciliid Brachyrhaphis episcopi (Steindachner 1878) exposed to different levels of predation pressure differ in cerebral lateralization (Brown et al ., 2004, 2007a), boldness (Brown et al ., 2005), aggression (Archard \& Braithwaite 2011a), exploration and activity (Archard \& Braithwaite 2011b). A significant relationship between lateralization and boldness was also reported in cichlids, with bolder individuals more strongly lateralized when exploring a familiar environment (Reddon \& Hurd, 2009b). In contrast, Dadda et al . (2007) found no link between coping style and laterality in selected lines of poeciliids. This link between cerebral lateralization and personality could prove crucial to understanding the maintenance of individual variability but to date the nature of the relationship is equivocal.

While previous studies have examined the relationship between individual differences in cerebral lateralization and single personality traits, this study aimed to explore a whole suite of behavioural traits in a wild population of guppies Poecilia reticulata Peters 1859. In the past, behavioural ecologists have studied behaviours in isolation; however, a more modern approach demands that multiple behaviours are examined in an integrated, holistic manner (Sih et al ., 2004). Behavioural syndromes, correlations between behaviours that are consistent across time and ecological contexts, have become an increasingly popular focus of research in recent years (Moretz et al ., 2007; Garamszegi et al ., 2009; Gabriel \& Black, 2010). These types of correlations may have significant ecological and evolutionary consequences, explaining not only the maintenance of individual variation in behaviour, but also the presence of seemingly non-adaptive behaviours in populations, as well as important demographic factors 
such as species distributions and dispersal potential (Sih et al ., 2004, 2012; Sih \& Bell, 2008; Cote et al ., 2010).

Perhaps the best studied personality axis is the shy-bold continuum, with boldness broadly defined as the propensity to take risks and explore in novel contexts (Wilson et al ., 1993, 1994). Individual variation in boldness has been demonstrated for a wide variety of taxa and is influenced by a range of factors including size (Brown \& Braithwaite, 2004), sex (Brown et al ., 2005; Harris et al ., 2010; Piyapong et al ., 2010), predation pressure (Magnhagen \& Borcherding, 2008; Archard \& Braithwaite, 2011a), nutritional state (Harcourt et al ., 2009) and the captive environment (Wilson et al ., 1994). Boldness is also heritable (Brown et al ., 2007b), highly correlated with fitness, associated with predator inspection, anti-predator defences (Toms et al ., 2010) and body condition (Brown et al ., 2007c). In P. reticulata, females prefer mating with bolder males irrespective of their colouration, leading to greater reproductive success in these individuals (Godin \& Dugatkin, 1996).

Other well-studied behavioural traits that are known to correlate with boldness include activity and aggression (Sih et al ., 2004). Archard \& Braithwaite (2011a, b) reported an aggressiveness-activityexploration-boldness syndrome associated with predation pressure in two populations of the tropical poeciliid $B$. episcopi ; individuals from high-predation areas were bolder, less aggressive and more active than those from low-predation areas. Similarly, Huntingford (1976) observed an aggression-boldness syndrome in the three-spined stickleback Gasterosteus aculeatus L. 1758 in one of the earliest demonstrations of a behavioural syndrome, whereby individuals who showed greater boldness towards a predator exhibited higher levels of territorial aggression. More recently, all three of these behaviours have been found to be correlated as an activity-aggression-boldness syndrome in some populations of $G$. aculeatus, with different ecological and developmental scenarios favouring different suites of traits (Bell \& Stamps, 2004; Bell, 2005; Dingemanse et al ., 2007). While activity, aggression and boldness traits have been the focus of much research, less attention has focused on sociability; however, an inverse relationship between aggression and schooling tendency has been demonstrated in $P$. reticulata (Magurran \& Seghers, 1991). Similarly, Budaev (1997) found links between sociability and exploration (locomotion) in a social context while examining personality traits in $P$. reticulata. Sociability is also an important personality dimension and has been linked with fitness related traits such as dispersal tendency (Cote et al ., 2010).

Here the relationship between individual variation in cerebral lateralization and three behavioural traits, boldness, activity and sociability, was examined in a wild population of feral $P$. reticulata. Poecilia reticulata is a model organism for this type of study because of the extensive knowledge of their biology and behavior (Budaev, 1997). This project aimed to determine (1) whether variation in the strength and direction of cerebral lateralization is linked with variation in boldness, activity and sociability and (2) whether boldness, activity and sociability are correlated as behavioural syndromes.

\section{MATERIALS AND METHODS}

\section{SUBJECTS}

Feral $P$. reticulata were collected from a freshwater drainage ditch at Fannie Bay, Darwin, in May 2011, and transported to the Central Animal House at Macquarie University in Sydney, New South Wales, Australia. The ditch is connected to an estuarine creek known to contain numerous large piscine predators.

Eighty (40 male and 40 female) $P$. reticulata were used in this study, with all tests carried out between August 2011 and February 2012. All 80 P. reticulata were run through the four behavioural tasks listed 
below. Poecilia reticulata were housed in single sex shoals of 10 individuals in replicate aquaria (38 $\mathrm{cm} \times$ $21 \mathrm{~cm}$ and $28 \mathrm{~cm}$ deep). Each aquarium was furnished with river gravel and Java moss to provide shelter. Water quality was maintained using an internal filter augmented by monthly water changes. Poecilia reticulata were fed commercial flake food (Tetramin tropical flakes; www.tetra-fish.com) daily and occasionally offered bloodworms Chironomus sp. and boiled lettuce. Room temperature was maintained at $25^{\circ} \mathrm{C}$ with a $12 \mathrm{~L}: 12 \mathrm{D}$ photoperiod (lights on at 0700 hours). Females were anaesthetized using $0 \cdot 1 \mathrm{mg}$

$\mathrm{I}^{-1}$ MS-222 (tricaine methanesulphonate) with a sodium bicarbonate buffer and injected with elastomer tags (North-West Marine Technology; www.nmt.us) to permit individual identification. Three colours (orange, yellow and green) injected into one of four locations (front left, front right, back left and back right) were used to provide 12 unique tag combinations that were repeated in each group. Males were photographed on their left side and their unique pattern of colouration sketched. Particular attention was placed on the orange carotenoid and black melanin spots and the shape of the caudal and dorsal fins. Standard length (LS; the distance from the tip of the snout to the caudal peduncle) was measured to the nearest $0 \cdot 1 \mathrm{~mm}$ using callipers.

\section{LATERALIZATION}

The apparatus used was based on that of previous studies (Bisazza et al ., 1998b, 2000a; Brown et al ., 2007a). It consisted of a large aquarium (92 cm $\times 39 \mathrm{~cm}$ and $36 \mathrm{~cm}$ deep) with a black perspex runway down the centre $(25 \mathrm{~cm} \times 10 \mathrm{~cm})$, opening out at each end to form a dumbbell shape [Fig. 1(a)]. The water level was maintained at $12 \mathrm{~cm}$ and a fluorescent lamp hung directly above the runway to prevent a light-induced turning bias. Each $P$. reticulate was tested against two types of stimuli: (1) a neutral (or control) stimulus in the form of a clear plastic holding tank $(7.5 \mathrm{~cm} \times 7.5 \mathrm{~cm}$ and $7.5 \mathrm{~cm}$ deep) and (2) a social stimulus comprising an unfamiliar female in an identical holding tank. The females were also used as social stimuli for males since males tend to behave antagonistically towards each other. No evidence of sexual displays towards stimulus females was observed and thus it was assumed that males also perceived the shoal in a manner similar to the females in this context. The stimuli were placed behind a vertical bar barrier covered in fine black mesh so as to hinder but not eliminate viewing [Fig. 1(b)].

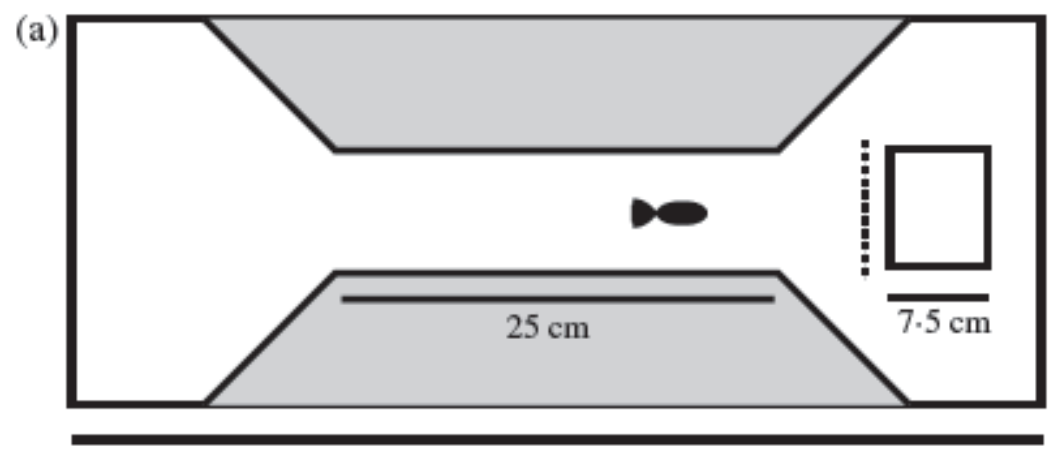

(b)

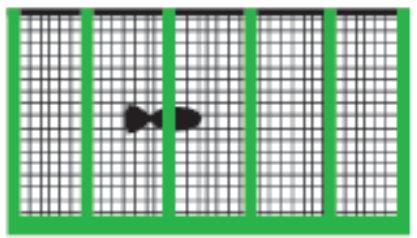

$92 \mathrm{~cm}$

Fig. 1. (a) Schematic representation of the detour apparatus. The subject swims down the central runway where it must make either a left or right turn to detour the vertical bar barrier ( ) and view the stimulus. (b) The vertical bar barrier (shown obscuring the social stimulus). The stimulus is moved to the other end of the runway between exposures. 
Each $P$. reticulata was placed in the apparatus for an initial acclimation period of 3 min, during which no stimuli or barriers were present. Following this, the subject was confined to one end of the tank using a black perspex barrier while the stimulus was positioned at the opposite end. The perspex barrier was then removed, allowing the $P$. reticulata passage into the runway. A net was used to gently coax the $P$. reticulata towards the stimulus if necessary. At the end of the runway, the subject had to turn either left or right in order to detour the vertical bar barrier and get a clear view of the stimulus, allowing the assessment of the direction of laterality through eye preference. Since $P$. reticulata have little overlap in their visual fields, each eye effectively projects separately to the contralateral hemisphere. Thus a right turning $P$. reticulata uses its left eye to view the stimulus and the right hemisphere to process the information. The direction chosen was recorded once the subject's head was parallel to the barrier. Observations were taken from behind the aquarium, opposite to the direction of travel to prevent an observer-induced turning bias. The $P$. reticulata was then confined to the end of the tank for $20 \mathrm{~s}$ while the stimulus was switched to the opposite side and the test re-run. The procedure was repeated 10 times per trial for each of the two stimuli. Each fish underwent an additional settling period of 3 min before the stimulus was changed, with the stimuli alternating between neutral and social for each individual. Females were tested for lateralization three times for each stimulus in order to examine individual consistency over time, with a minimum period of $24 \mathrm{~h}$ between each trial. Males were tested once for each stimulus, since the results of the female tests suggested that their behavior was stable over the three exposures.

\section{BOLDNESS ASSAY}

The experimental arena consisted of a large aquarium $(91 \mathrm{~cm} \times 51 \mathrm{~cm}$ and $20 \mathrm{~cm}$ deep). Water depth was maintained at $12 \mathrm{~cm}$ and a heater was placed at the far end of the arena. Water temperature was noted daily to ensure consistent testing conditions. The aquarium was furnished with $2 \mathrm{~cm}$ of gravel; plastic plants, marbles, stones and Duplo (http://duplo.lego.com/) were scattered throughout the arena to create a novel testing environment. The position of these ornaments was randomized between trials. A starting box constructed of black Perspex $(9.5 \mathrm{~cm} \times 7.5 \times 14.5 \mathrm{~cm})$ was positioned on a white plastic semi-circle (9 $\mathrm{cm}$ radius) at one end of the aquarium. The box was fitted with an opaque lid and a sliding trapdoor, which could be opened remotely via a piece of fishing line (Brown et al ., 2005). Observations were taken from behind the starting box so as not to influence emergence times.

Each $P$. reticulata was gently introduced to the starting box where it was contained for a 2 min settling period before the trapdoor was then gently lifted. Boldness was measured as the time taken to cross the white semi-circle onto the gravel arena (Brown \& Braithwaite, 2004; Brown et al ., 2005, 2007b). If the subject had not emerged after $6 \mathrm{~min}$, the opaque lid was removed from the starting box to encourage the fish to emerge. At 8min the trial was terminated and the subject awarded a maximum possible score of $480 \mathrm{~s}$. All $P$. reticulate were tested for boldness twice, with an average period of 7 days between each trial.

\section{ACTIVITY ASSAY}

Activity levels were measured in 10 identical aquaria $(44 \mathrm{~cm} \times 24 \mathrm{~cm}$ and $24 \mathrm{~cm}$ deep) that were visually isolated from one another. River gravel $(2 \mathrm{~cm})$ was placed in each aquarium and water depth was maintained at $19 \mathrm{~cm}$. A grid consisting of $6.2 \mathrm{~cm} \times 6.2 \mathrm{~cm}$ squares was drawn on the front panel. Water temperature was continually monitored throughout the testing period. Observations were taken from behind a curtain using a webcam to prevent any observer-induced bias.

A single $P$. reticulata was placed in each aquarium the day before testing to allow it to acclimate to its surroundings. Movement was recorded in two dimensions (horizontal and vertical) over a 10 min period 
using the behavioural transcription programme EthoLog v2.2.5 (Ottoni, 2000; http://www.ip.usp.br/docentes/ebottoni/EthoLog/ethohome.html). Each $P$. reticulata was awarded a total activity score based on the number of transects that it crossed during the observational period. All tests were carried out between 1100 and 1300 hours and the order of testing randomized. All $P$. reticulata were tested twice for activity, with a minimum period of $48 \mathrm{~h}$ between each trial.

\section{SOCIABILITY}

A measure of sociability was used rather than aggression because it was difficult to induce aggressive behaviours in females. A small aquarium (22 cm $\times 15 \mathrm{~cm}$ and $15 \mathrm{~cm}$ deep) was placed inside a larger aquarium (44 cm $\times 24 \mathrm{~cm}$ and $24 \mathrm{~cm}$ deep) to create a transparent compartment. A shoal of six unfamiliar female $P$. reticulata was housed in the smaller tank as a social stimulus. A female stimulus shoal was used for both sexes simply because males are not attracted to shoals of males, on the contrary they are repelled by them. Given the novel environment, males treated the shoal in a similar manner to the females (i.e. as a social refuge). The large compartment was divided into five sections labelled $A$ to $E$ where $A$ was the column closest to the shoal and $E$ was the furthest column away. The water level was maintained at $12 \mathrm{~cm}$ to prevent escape of the shoal. Each test $P$. reticulata was introduced to the far end of the larger aquarium and allowed $5 \mathrm{~s}$ to settle before timing began. The proportion of time spent in each section over a period of 10 min was measured using EthoLog v. 2.2.5. Observations were taken from behind a curtain using a webcam placed in front of the grid. All $P$. reticulata were tested twice with a minimum period of $48 \mathrm{~h}$ between each trial.

\section{STATISTICAL ANALYSIS}

The detour data for each individual were converted into a 'laterality index' ( L; Bisazza et al ., 1998b), where $I_{L}=$ (number of right turns-number of left turns) per total number of turns. $I_{L}$ is a continuous variable with scores ranging from -1 to 1 , where positive scores indicate a right turn bias, negative scores a left turn bias and scores of 0 no turn bias. Repeated measure ANOVA was used to examine the effect of stimuli (repeated measure) and sex (fixed independent variable) on turn preferences. Analysis was performed using data from the females first trial. The laterality scores were all normally distributed and no transformations were required. Regression analysis was used to identify any correlations between lateralization and the three behavioural measures using StatView v. 5.0 .1 (www.sas.com/). I L was used to assess the direction of laterality and absolute values were used to assess the strength of laterality.

The boldness, activity and sociability data were $\log _{10}+1$ transformed to satisfy the assumption of normality. A sociability index $(I \mathrm{~s})$ was generated, where $I_{\mathrm{s}}=1000$ [(time spent in column $\mathrm{x}$ ) $\times$ (distance of column $x$ from the shoal +1$)]^{-1}$. I $S$ is a continuous variable, with higher scores indicating more social individuals. The analysis was conducted using the average scores of each individual for boldness, activity and sociability. Spearman rank correlations were used to assess the consistency of the behaviours over time. Regression analysis was performed in StatView v. 5.0.1 to identify any correlations, or behavioural syndromes, between the behaviours. A principal component analysis (PCA) examined the relationship between all personality measurements.

\section{ETHICAL NOTE}

All procedures carried out comply with the current Australian laws and were covered under ARA 2010/028 from the Macquarie University Animal Ethics Committee and the $P$. reticulata were rehomed after experimentation. During the marking procedure all $P$. reticulata fully recovered from anaesthetic within a couple of minutes and no fatalities were recorded. 
Table I. Spearman rank correlations $\left(r_{\mathrm{s}}\right)$ and associated $\boldsymbol{P}$-values for three repeated observations of laterality index

\begin{tabular}{|lcccc|}
\hline Treatment & Stat & $\mathbf{1 v . 2}$ & $\mathbf{2 v . 3}$ & $\mathbf{1 v . 3}$ \\
\hline Neutral stimulus & $r_{\mathrm{s}}$ & 0.357 & 0.250 & 0.318 \\
& $P$ & 0.026 & 0.118 & 0.047 \\
Social stimulus & $r_{\mathrm{s}}$ & 0.364 & 0.309 & 0.453 \\
& $P$ & 0.023 & 0.054 & 0.005 \\
\hline
\end{tabular}

\section{RESULTS}

Although female $P$. reticulata were significantly larger than the males (mean \pm S.E. $L_{S}$ females: $28 \cdot 36 \pm$ $0.41 \mathrm{~mm}, n=40$; males: $19.24 \pm 0.18 \mathrm{~mm}, n=40$; 2-sample $t$-test: $\left.t_{78}=20.59, P<0.001\right)$, $L_{s}$ was not significantly correlated with any of the personality variables measured $(P>0.05)$. Size, however, significantly influenced $I_{L}$ when viewing a neutral stimulus in females $\left(F_{1,38}=4 \cdot 703, P=0 \cdot 036\right)$ such that larger females were more strongly right biased. No relationship was observed in males.

The $I_{L}$ generated by the females was repeatable across all three replicates of the stimuli with the exception of the comparison between the second and third exposure to the neutral stimulus (Table I). All subjects showed a right bias at the population level when viewing the neutral and social stimuli. A significant interaction was observed between sex and stimuli $\left(F_{1,78}=8 \cdot 027, P=0.006\right)$ such that females were more strongly right biased than males while observing the neutral stimuli but less strongly biased than males when observing the social stimuli. Qualitatively similar results were obtained for the strength of laterality which is to be expected given the consistent right bias in the direction data.

Analysis of the personality assays showed that individuals demonstrated consistency between trial 1 and trial 2 for all variables (Table II). Regression analysis revealed a positive correlation between boldness and activity, but this effect was stronger in males (total: $r^{2}=0 \cdot 134, F_{1,38}=12 \cdot 04, P<0 \cdot 001$; females: $r^{2}=$ $0.060, F_{1,38}=2.435, P=0.127$; males: $r^{2}=0.083, F_{1,38}=3.472, P=0.070$; Fig. 2). The lack of significance once the data was split by sex was due to a loss of power. Bold $P$. reticulata were more active than shy $P$. reticulata. A significant relationship between $I_{\mathrm{S}}$ and boldness was also found, but only in males $\left(r^{2}=0.131, F_{1,38}=5 \cdot 733, P=0.022\right)$. The reciprocal relationship between sociability and activity also approached significance in males $\left(r^{2}=0 \cdot 075, F_{1,38}=3 \cdot 097, P=0 \cdot 086\right)$.

Table II. Spearman rank correlations $\left(r_{\mathrm{s}}\right)$ and associated $P$-values for repeated tests of the three behavioural measures in male and female Poecilia reticulate

\begin{tabular}{|c|c|c|c|c|}
\hline \multirow[b]{2}{*}{ Trait } & \multicolumn{2}{|c|}{ Females } & \multicolumn{2}{|c|}{ Males } \\
\hline & $\left(r^{2}\right)$ & $P$ & $\left(r^{2}\right)$ & $P$ \\
\hline Boldness & 0.509 & 0.002 & 0.361 & 0.024 \\
\hline Activity & 0.453 & 0.005 & 0.396 & 0.013 \\
\hline Sociability & 0.406 & 0.011 & 0.563 & $<0.001$ \\
\hline
\end{tabular}

The PCA resulted in two principal components (PCs), together summarizing $78 \%$ of the variation in the three behaviours. Factor 1 accounted for $46 \%$ of the variation and described the boldness-activity syndrome, with negative scores indicating bold and active individuals. Factor 2 accounted for $33 \%$ of the variation and summarized sociability, with negative scores representing more social individuals. Males 
tended to be more active and bold but less social than females (Fig. 3). When the analysis was split by sex, the data supported the general view of a behavioural syndrome involving all three measurements in males but not females (Bartlett's $X^{2}=3 \cdot 305, P=0 \cdot 347$ and Bartlett's $X^{2}=9 \cdot 842, P=0 \cdot 020$ for females and males).

There were no significant correlations between $I_{L}$ and any of the behaviours measured in either sex $(P>$ $0.05)$. This was similar for the relationship between absolute laterality index and behaviours, with the exception of the absolute value of the laterality index and boldness in females which showed a strong trend $\left(F_{1,39}=4 \cdot 366, P=0.051\right)$. Strongly lateralized females viewing social stimuli tended to be bolder than weakly lateralized females (Fig. 4).

\section{DISCUSSION}

Contrary to expectations, little evidence that variation in the strength and direction of cerebral lateralization is correlated with variation in boldness, activity or sociability was found in either sex of $P$. reticulata. Only the strength of laterality, while females viewed a social stimulus, was related to boldness but the relationship was weak. These results are broadly consistent with previous studies which demonstrated a link between the strength of lateralization, but not direction, and two personality traits, boldness and aggressiveness (Reddon \& Hurd, 2008, 2009b). As in this study, the relationship between the aggressiveness and the strength of laterality in convict cichlids Amatitlania nigrofasciata (Günther 1867) varied depending on the sex of the subject (Reddon \& Hurd, 2008). Clotfelter \& Kuperberg (2007) also examined the relationship between laterality and aggression in six species of anabantoids, finding no link at the species or individual level. Clotfelter \& Kuperberg (2007) used only males and perhaps this explains the lack of a relationship. There appears to be little evidence to suggest that personality traits explain the maintenance of individual variability in lateralization as hypothesized.

All three behavioural traits measured here were highly repeatable over time in both sexes which is indicative of personality traits in $P$. reticulata. Moreover, significant relationships existed between traits, especially in males. Overall, a strong correlation between activity and boldness existed but when split by sex the relationship only approached significance in males. Nevertheless, examination of the gradient for males and females shows negligible differences, suggesting that both sexes may have an activityboldness syndrome. Similarly, Piyapong et al . (2010) reported a boldness syndrome across social contexts only in males. Smith \& Blumstein (2010) reported a positive correlation between activity in an open field, boldness towards a predator and inspection of a novel object in a captive population of $P$. reticulata. Furthermore, individuals exhibiting this syndrome survived longer in a staged predation experiment, suggesting that the observed activity-boldness syndrome may be adaptive in populations of $P$. reticulata exposed to considerable predation risk. This study used $P$. reticulata collected from a freshwater drainage ditch upstream of an estuarine creek where many large piscine predators are present, providing support for an adaptive hypothesis. Archard \& Braithwaite $(2011 a, b)$ reported a similar activity-boldness syndrome in a related species, $B$. episcopi, with individuals from high-predation areas more explorative, active and bold than those from low-predation areas.

Only males showed evidence of a three-way relationship between boldness, activity and sociability in this population of $P$. reticulata. Using the correlation approach, two of these relationships showed strong trends but were not statistically significant. A number of studies have reported an activity-aggressionboldness syndrome in populations of G. aculeatus (Bell \& Stamps, 2004; Bell, 2005; Dingemanse et al ., 2007). These studies on $G$. aculeatus have illustrated the flexibility of behavioural syndromes, demonstrating that different suites of traits can be favoured under different developmental and ecological circumstances. Dingemanse et al . (2007) examined behavioural correlations in 12 populations of $G$. 
aculeatus, showing that the activityaggression-boldness syndrome was only present in populations exposed to high levels of predation pressure. If this syndrome is maintained by high levels of predation pressure, it is difficult to envisage a scenario that favours its maintenance in males but not in females. Generally it is agreed that females are more risk sensitive and males tend to be risk prone. It could be argued, however, that there may indeed be stronger selection on male behaviour given their risk prone life-history strategy. Future studies should examine multiple populations spanning a range of predation pressures throughout their development in order to improve understanding of behavioural syndromes in this model species.
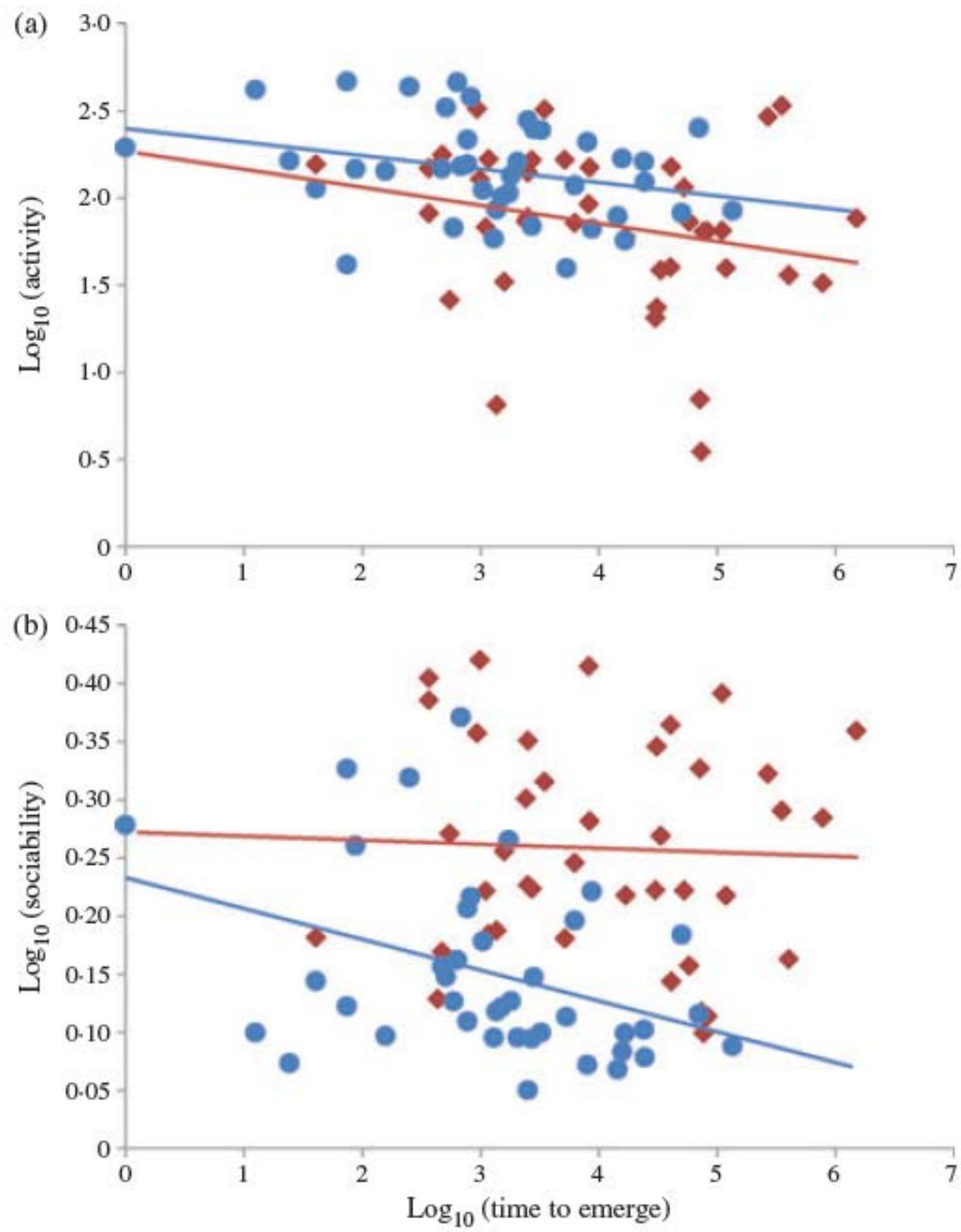

Fig. 2. Bivariate scattergram showing the relationship between (a) boldness and activity and (b) boldness and sociability in female $(\bullet)$ and male $(\bullet)$ Poecilia reticulata. Note that higher emergence scores represent shyer individuals. The relationships are only significant for males and the curves were fitted by: (a) $y=-0$. $077 x+2.396$ and (b) $y=-0.26 x+0.233$. 


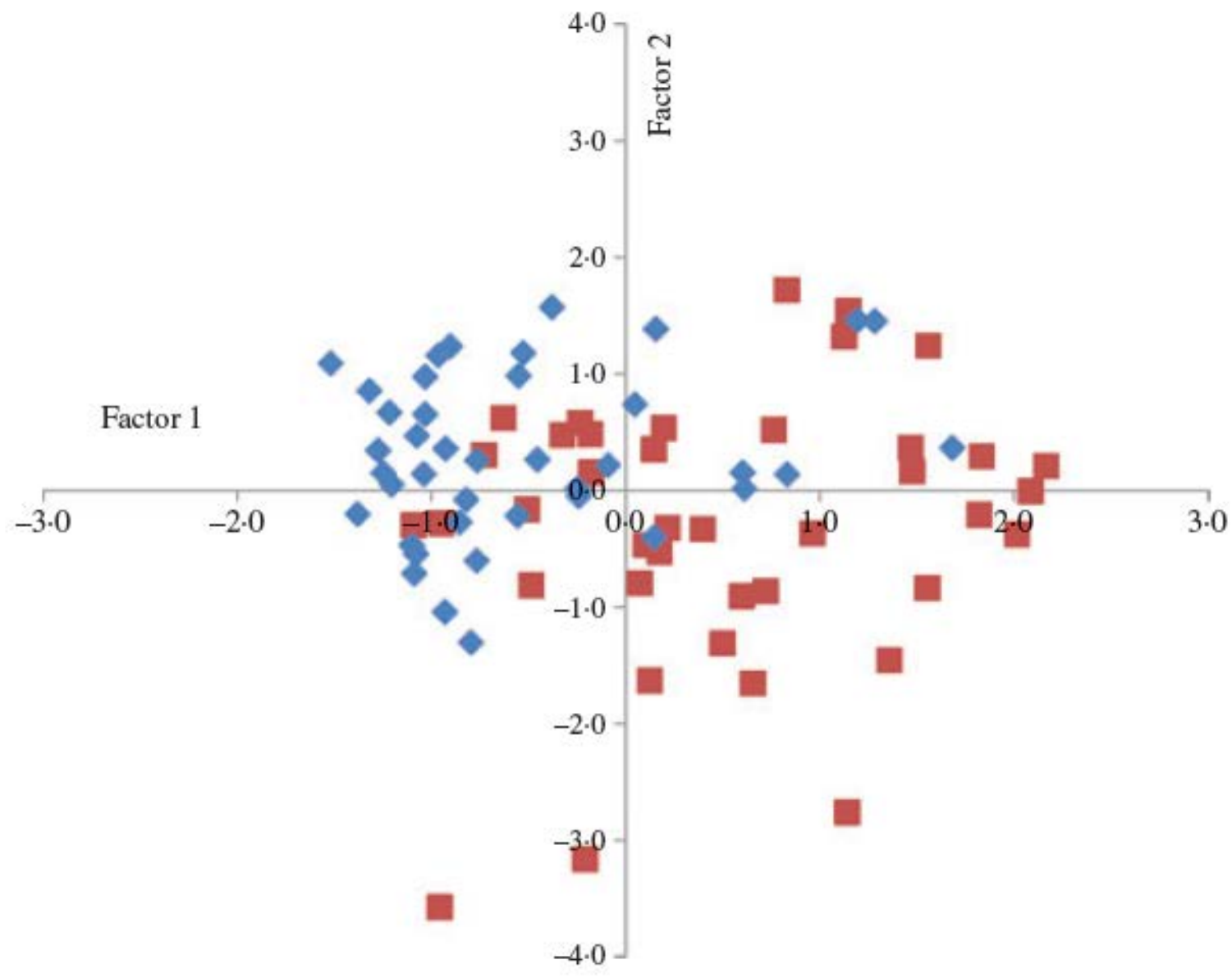

Fig. 3. Bivariate scattergram showing the relationship between factors 1 and 2 in female ( $\square$ ) and male ( $)$ Poecilia reticulata, with negative factor 1 scores indicating bold and active individuals and negative factor 2 scores indicating social individuals. Males tend to be bold, active and antisocial while females exhibit greater variance across both dimensions.

The results from the linear regression analyses were further supported by a PCA examining the relationship between the three behavioural traits in the study population. The PCA conducted on the entire dataset resulted in two PCs summarizing $78 \%$ of the variation in the three behaviours. PC1 accounted for $46 \%$ of the variation, describing the same activity-boldness syndrome as the regression analysis, while PC2 accounted for $35 \%$ of the variation, summarizing an additional sociability component. Interestingly, a significant positive relationship was found between PC1 and PC2 but only in male $P$. reticulata, indicating the presence of an activity-sociability-boldness syndrome similar to that in $G$. aculeatus (Bell \& Stamps, 2004; Bell, 2005; Dingemanse et al ., 2007). When the data were split by sex, only a single factor emerged that comprised all three variables but this analysis was only significant in males. Males that were more active in a familiar environment were quicker to emerge into a novel environment and spent more time schooling with conspecifics. Compared to regression analysis, PCA is a more powerful approach to studying animal personality, examining multiple behaviours in an integrated, holistic fashion ideal for future studies examining behavioural syndromes (Sih et al ., 2004). 


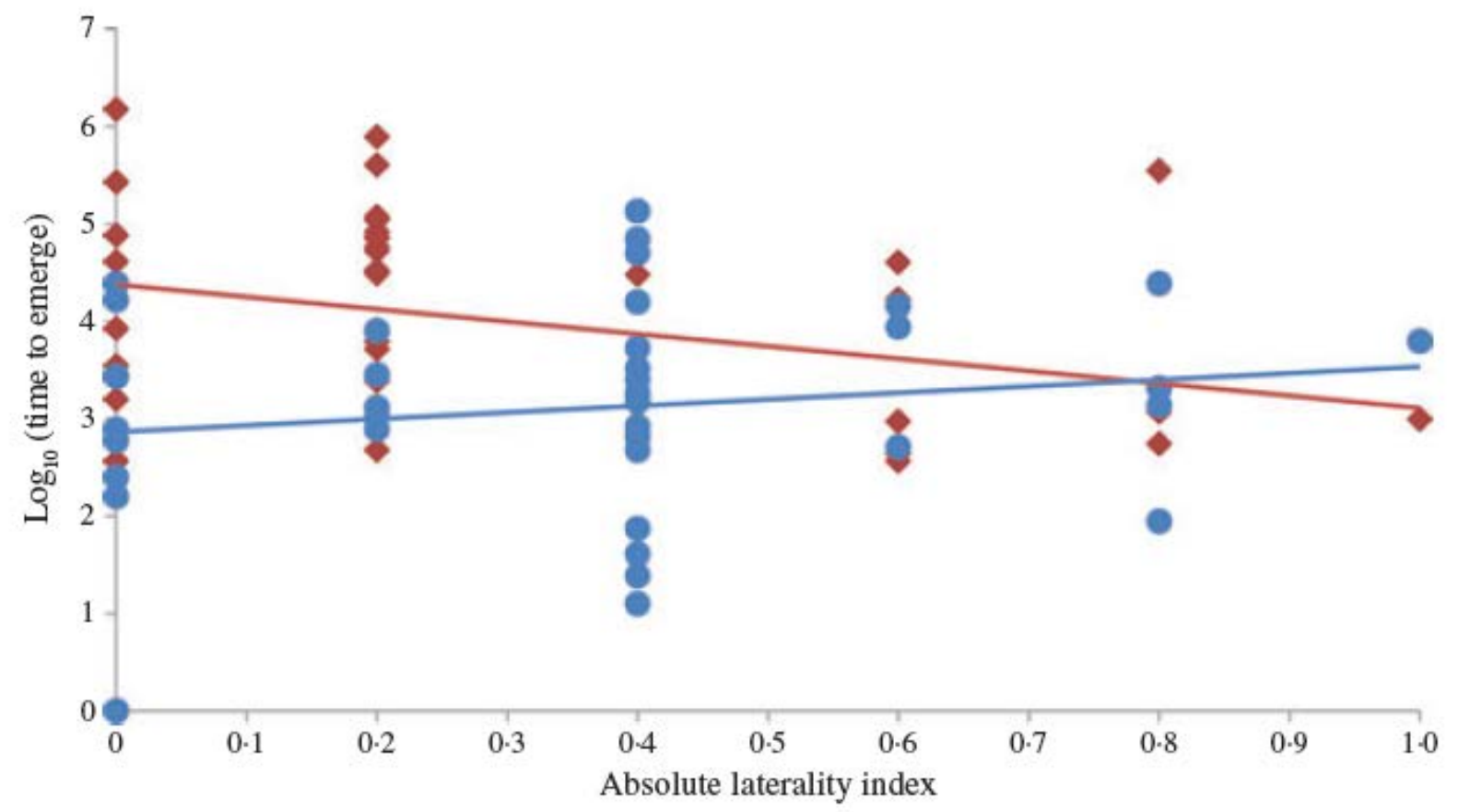

Fig. 4. The relationship between the strength of laterality (absolute laterality index) and boldness (time to emerge) in female ( $\bullet$ and male ( $\bullet$ ) Poecilia reticulata. Only females showed a relationship that was close to significance $\left(r 2=0 \cdot 096, F_{1,39}=4 \cdot 366, P=0 \cdot 051\right)$.

A precautionary note is made here with regard to the sociability test. Both males and females were exposed to a social group comprising females. This was done simply because males are not attracted to other males and observations suggest that both males and females treated the shoal as a social refuge (pers. obs.). It is possible, however, that some of the males were sexually stimulated and therefore highly motivated to school, although no evidence of this was seen during our observations (i.e. no displays were observed) and males still spent less time schooling than females.

These data also clearly show that male $P$. reticulata tended to be active, bold and antisocial as a whole. Females on the other hand were more varied in their activity and boldness levels, but tended to be less active, less bold and more social than males (Fig. 3). While consistent, inter-individual differences in behaviour may seem detrimental from an adaptive perspective, evidence is rapidly accumulating that certain life-history tradeoffs may favour the evolution of animal personalities (Wolf et al ., 2007). In agreement with the observations here, life-history theory predicts that female $P$. reticulata will be more risk-averse and spend more time schooling than males. Since females are regularly surrounded by potential mating partners and can continue to produce new broods using stored sperm even in the absence of mates, their reproductive success is maximized by simply staying alive; fecundity is positively correlated with body size, which increases with age (Harris et al ., 2010). Males on the other hand benefit from a high-risk strategy, continuing to pursue mating opportunities at the risk of exposure to predators and other dangers (Harris et al ., 2010). While this study found no effect of body size on any of the behavioural traits within sexes, size differences between the sexes may further explain the behavioural differences observed. Male $P$. reticulata are smaller than females, and predicted to be more active and emerge from shelter sooner as a consequence of their faster metabolic rate (Brown \& Braithwaite, 2004). Future studies should assess the heritability and fitness consequences of different behavioural types 
directly, thus furthering understanding of the development and maintenance of animal personality from within an evolutionary framework.

We thank S. Young and R. Woods for assisting with the personality scores for the male $P$. reticulata, L. Oulton for taking care of the $P$. reticulata on public holidays and during leave. C.B. was supported by an Australian Research Fellowship from the ARC.

\section{References}

Archard, G. A. \& Braithwaite, V. A. (2011a). Increased exposure to predators increases both exploration and activity level in Brachyrhaphis episcopi . Journal of Fish Biology 78, 593-601.

Archard, G. A. \& Braithwaite, V. A. (2011b). Variation in aggressive behaviour in the poeciliid fish Brachyrhaphis episcopi : population and sex differences. Behavioural Processes 86, 52-57.

Bell, A. M. (2005). Behavioural differences between individuals and two populations of stickleback (Gasterosteus aculeatus). Journal of Evolutionary Biology 18, 464-473.

Bell, A. M. \& Stamps, J. A. (2004). Development of behavioural differences between individuals and populations of sticklebacks, Gasterosteus aculeatus. Animal Behaviour 68, 1339-1348.

Bisazza, A. \& Brown, C. (2011). Lateralization of cognitive function in fish. In Fish Cognition and Behaviour, 2nd edn (Brown, C., Laland, K. \& Krause, J., eds), pp. 298-324. Oxford: Blackwell Publishing.

Bisazza, A. \& Dadda, M. (2005). Enhanced schooling performance in lateralized fishes. Proceedings of the Royal Society B 272, 1677-1681.

Bisazza, A., Rogers, L. J. \& Vallortigara, G. (1998a). The origins of cerebral asymmetry: a review of evidence of behavioural and brain lateralization in fishes, reptiles and amphibians. Neuroscience and Biobehavioral Reviews 22, 411-426.

Bisazza, A., Facchin, L., Pignatti, R. \& Vallortigara, G. (1998b). Lateralization of detour behaviour in poeciliid fish: the effect of species, gender and sexual motivation. Behavioural Brain Research 91, 157-164.

Bisazza, A., Cantalupo, C., Capocchiano, M. \& Vallortigara, G. (2000a). Population lateralization and social behaviour: a study with 16 species of fish. Laterality 5, 269-284.

Bisazza, A., Facchin, L. \& Vallortigara, G. (2000b). Heritability of lateralization in fish: concordance of right-left asymmetry between parents and offspring. Neurospychologia 38, 907-912.

Bisazza, A., De Santi, A., Bonso, S. \& Sovrano, V. A. (2002). Frogs and toads in front of a mirror: lateralisation of response to social stimuli in tadpoles of five anuran species. Behavioural Brain Research 134, 417-424.

Bisazza, A., Dadda, M. \& Cantalupo, C. (2005). Further evidence for mirror-reversed laterality in lines of fish selected for leftward or rightward turning when facing a predator model. Behavioural Brain Research 156, 165-171.

Brown, C. (2005). Cerebral lateralisation, social constraints, and coordinated anti-predator responses. Behavioral and Brain Sciences 28, 591.

Brown, C. \& Braithwaite, V. A. (2004). Size matters: a test of boldness in eight populations of the poeciliid Brachyraphis episcopi . Animal Behaviour 68, 1325-1329.

Brown, C., Gardner, C. \& Braithwaite, V. A. (2004). Population variation in lateralized eye use in the poeciliid Brachyraphis episcopi . Proceedings of the Royal Society B 271, S455-S457. 
Brown, C., Jones, F. \& Braithwaite, V. A. (2005). In situ examination of boldness-shyness traits in the tropical poeciliid, Brachyraphis episcopi . Animal Behaviour 70, 1003-1009.

Brown, C., Western, J. \& Braithwaite, V. A. (2007a). The influence of early experience on, and inheritance of, cerebral lateralization. Animal Behaviour 74, 231-238.

Brown, C., Burgess, F. \& Braithwaite, V. A. (2007b). Heritable and experiential effects on boldness in a tropical poeciliid. Behavioural Ecology and Sociobiology 62, 237-243.

Brown, C., Jones, F. C. \& Braithwaite, V. A. (2007c). Correlation between boldness and body mass in natural populations of Brachyraphis episcopi . Journal of Fish Biology 71, 1509-1601.

Budaev, S. V. (1997). Personality in the guppy (Poecilia reticulata): a correlational study of exploratory behavior and social tendency. Journal of Comparative Psychology 3, 399-411.

Byrne, R. A., Kuba, M. \& Griebel, U. (2002). Lateral asymmetry of eye use in Octopus vulgaris. Animal Behaviour 64, 461-468.

Casperd, J. M. \& Dunbar, R. I. M. (1996). Asymmetries in the visual processing of emotional cues during agonistic interactions by gelada baboons. Behavioural Processes 37, 57-65.

Clotfelter, E. D. \& Kuperberg, E. S. (2007). Cerebral lateralization and its relationship to phylogeny and aggression in anabantoid fishes. Brain, Behavior and Evolution 69, 169-175.

Cote, J., Fogarty, S., Weinersmith, K., Brodin, T. \& Sih, A. (2010). Personality traits and dispersal tendency in the invasive mosquitofish (Gambusia affinis). Proceedings of the Royal Society $B$ 277, 1571-1579.

Dadda, M. \& Bisazza, A. (2006). Does brain asymmetry allow efficient performance of simultaneous tasks? Animal Behaviour 72, 523-529.

Dadda, M., Zandona, E. \& Bisazza, A. (2007). Emotional responsiveness in fish from lines artificially selected for a high or low degree of laterality. Physiology and Behavior 92, 764-772.

Dadda, M., Zandon`a, E., Agrillo, C. \& Bisazza, A. (2009). The costs of hemispheric specialization in a fish. Proceedings of the Royal Society B 276, 4399-4407.

De Santi, A., Bisazza, A., Cappelletti, M. \& Vallortigara, G. (2000). Prior exposure to a predator influences lateralization of cooperative predator inspection in the guppy, Poecilia reticulata. Italian Journal of Zoology 67, 175-178.

Diekamp, B., Regolin, L., Gunturkun, O. \& Vallortigara, G. (2005). A left-sided visuospatial bias in birds. Current Biology 15, R372-R373.

Dingemanse, N. J., Wright, J., Kazem, A. J. N., Thomas, D. K., Hickling, R. \& Dawnay, N. (2007). Behavioural syndromes differ predictably between 12 populations of three-spined stickleback. Journal of Animal Ecology 76, 1128-1138.

Dinsdale, N. L., Reddon, A. R. \& Hurd, P. L. (2011). Sex differences in the relationship between aggressiveness and the strength of handedness in humans. Laterality: Asymmetries of Body, Brain and Cognition 16, 385-400.

Garamszegi, L. Z., Eens, M. \& T"or"ok, J. (2009). Behavioural syndromes and trappability in free-living collared flycatchers, Ficedula albicollis. Animal Behaviour 77, 803-812.

Gabriel, P. O. \& Black, J. M. (2010). Behavioural syndromes in Steller's jays: the role of time frames in the assessment of behavioural traits. Animal Behaviour 80, 689-697.

Ghirlanda, S. \& Vallortigara, G. (2004). The evolution of brain lateralization: a game theoretical analysis of population structure. Proceedings of the Royal Society B 271, 853-857.

Godin, J.-G. J. \& Dugatkin, L. A. (1996). Female mating preference for bold males in the guppy, Poecilia reticulata. Proceedings of the National Academy of Sciences of United States of America 93, 10262-10267.

Harcourt, J. L., Sweetman, G., Johnstone, R. A. \& Manica, A. (2009). Personality counts: the effect of boldness on shoal choice in three-spined sticklebacks. Animal Behaviour 77, 1501-1505. 
Harris, S., Ramnarine, I. W., Smith, H. G. \& Pettersson, L. B. (2010). Picking personalities apart: Estimating the influence of predation, sex and body size on boldness in the guppy Poecilia reticulata. Oikos 119, 1711-1718.

Heuts, B. A. \& Brunt, T. (2005). Behavioral left-right asymmetry extends to arthropods. The Behavioral and Brain Sciences 28, 601-602.

Hori, M. (1993). Frequency-dependent natural selection in handedness of scale-eating cichlid fish. Science 260, 216-219.

Huntingford, F. A. (1976). The relationship between anti-predator behaviour and aggression among conspecifics in the three-spined stickleback, Gasterosteus aculeatus. Animal Behaviour 24, 245260.

Letzkus, P., Ribi, W. A., Wood, J. T., Zhu, H., Zhang, S.-W. \& Srinivasan, M. V. (2006). Lateralization of olfaction in the honeybee Apis mellifera. Current Biology 16, 1471-1476.

Magat, M. \& Brown, C. (2009). Laterality enhances cognition in Australian parrots. Proceedings of the Royal Society B 276, 4155-4162.

Magnhagen, C. \& Borcherding, J. (2008). Risk-taking behaviour in foraging perch: Does predation pressure influence age-specific boldness? Animal Behaviour 75, 509-517.

Magurran, A. E. \& Seghers, B. H. (1991). Variation in schooling and aggression amongst guppy (Poecilia reticulata) populations in Trinidad. Behaviour 118, 214-234.

Moretz, J. A., Martina, E. P. \& Robison, B. D. (2007). Behavioral syndromes and the evolution of correlated behavior in zebrafish. Behavioural Ecology 18, 556-562.

Ottoni, E. B. (2000). EthoLog 2.2 - a tool for the transcription and timing of behavior observation sessions. Behavior Research Methods, Instruments, and Computers 32, 446-449.

Piyapong, C., Krause, J., Chapman, B. B., Ramnarine, I. W., Louca, V. \& Croft, D. P. (2010). Sex matters: a social context to boldness in guppies (Poecilia reticulata). Behavioural Ecology 21, 3-8.

Reddon, A. R. \& Balshine, S. (2010). Lateralization in response to social stimuli in a cooperatively breeding cichlid fish. Behavioural Processes 85, 68-71.

Reddon, A. R. \& Hurd, P. L. (2008). Aggression, sex and individual differences in cerebral lateralization in a cichlid fish. Biology Letters 4, 338-340.

Reddon, A. R. \& Hurd, P. L. (2009a). Sex differences in the cerebral lateralization of a cichlid fish when detouring to view emotionally conditioned stimuli. Behavioural Processes 82, 25-29.

Reddon, A. R. \& Hurd, P. L. (2009b). Individual differences in cerebral lateralization are associated with shy-bold variation in the convict cichlid. Animal Behaviour 77, 189-193.

Robins, A., Chen, P., Beazley, L. D. \& Dunlop, S. A. (2005). Lateralized predatory responses in the ornate dragon lizard (Ctenophorus ornatus). NeuroReport 16, 849-852.

Rogers, L. J. (1996). Behavioral, structural and neurochemical asymmetries in the avian brain: a model system for studying visual development and processing. Neuroscience and Biobehavioral Reviews 20, 487-503.

Rogers, L. J. (2000). Evolution of hemispheric specialization: advantages and disadvantages. Brain and Language 73, 236-253.

Rogers, L. J. (2002). Lateralization in vertebrates: its early evolution, general pattern, and development. Advances in the Study of Behaviour 31, 107-161.

Rogers, L. I. \& Andrew, R. (2002). Comparative Vertebrate Lateralization. Cambridge: Cambridge University Press.

Sih, A. \& Bell, A. M. (2008). Insights for behavioral ecology from behavioral syndromes. Advances in the Study of Behaviour 38, 227-281.

Sih, A., Bell, A. M. \& Johnson, C. (2004). Behavioural syndromes: an ecological and evolutionary overview. Trends in Ecology and Evolution 19, 372-378.

Sih, A., Cote, J., Evans, M., Fogarty, S. \& Pruitt, J. (2012). Ecological implications of behavioural syndromes. Ecology Letters 15, 278-289. 
Smith, B. R. \& Blumstein, D. T. (2010). Behavioral types as predictors of survival in Trinidadian guppies (Poecilia reticulata). Behavioural Ecology 21, 919-926.

Sovrano, V. A. (2004). Visual lateralization in response to familiar and unfamiliar stimuli in fish. Behavioural Brain Research 152, 385-391.

Toms, C. N., Echevarria, D. J. \& Jouandot, D. J. (2010). A methodological review of personality-related studies in fish: focus on the shy-bold axis of behavior. International Journal of Comparative Psychology 23, 1-25.

Vallortigara, G. \& Rogers, L. J. (2005). Survival with an asymmetrical brain: advantages and disadvantages of cerebral lateralization. Behavioural Brain Science 28, 575-633.

Wilson, D. S., Coleman, K., Clark, A. B. \& Biederman, L. (1993). Shy-Bold continuum in pumpkinseed sunfish (Lepomis gibbosus): an ecological study of a psychological trait. Journal of Comparative Psychology 107, 250-260.

Wilson, D. S., Clark, A. B., Coleman, K. \& Dearstyne, T. (1994). Shyness and boldness in humans and other animals. Trends in Ecology and Evolution 9, 442-446.

Wolf, M., van Doorn, S., Leimar, O. \& Weissing, F. J. (2007). Life-history trade-offs favour the evolution of animal personalities. Nature 447, 581-585. 